\title{
Call for action: Rare plasma related disorders
}

\author{
Jorgo Chatzimarkakis* and Miroslav Mikolasik \\ European Parliament, Brussels, Belgium
}

Rare Diseases are rightly seen as a growing European health priority. Both the European Commission and several EU Council Presidencies have held Rare Diseases as a priority area in healthcare policy. Many Rare Diseases cannot be diagnosed or treated. Rare plasma disorders can be diagnosed and successfully treated, but unacceptable diagnosis rates for some plasma disorders means that treatment can only begin late, or not at all.

We believe that the European Commission proposals are a positive step that must be supported by EU Member States.

Rare Diseases include over 200 plasma protein disorders such as Haemophilia, Primary Immunodeficiencies, Guillain-Barré syndrome, $\mathrm{C} 1$ inhibitor deficiencies and Alpha-1 Antitrypsin Deficiency many of which are treated with therapies derived from human plasma. The rarity of some of these disorders often means that information on treatment options, symptoms, diagnosis and access to treatment is not optimal and that unnecessary associated healthcare costs are incurred due to a higher rate of hospitalisation, increased number of missed days of school and work and increased infection rates.

We assert and emphasize that the following actions should be supported by the European Parliament, European Commission and European Council:

1. Each EU Member State should have a dedicated Rare Diseases action plan, using tools such as professionally run national patient registries and networks of reference centres for diagnosis and treatment, as proposed by the European Commission in November 2008.

2. European patients have the right to access the treatment that they need. In the case of life-threatening plasma protein disorders, this requires the widest possible access for patients to plasma protein therapies and the implementation of appropriate treatment levels of care, especially in EU Member States where access to treatment is restricted and/or not optimal.

3. The need for an adequate supply of safe and high quality human plasma for further manufacturing into therapeutic products.

\footnotetext{
${ }^{*}$ Corresponding author: Jorgo Chatzimarkakis, ASP 10G114, 60, rue Wiertz, B-1047 Brussels, Belgium. Tel.: +32 22847 149; Fax: +32 22849 149; E-mail: jorgo.chatzimarkakis-assistant@europarl. europa.eu.
} 
4. It is proposed to create a European Parliament Interest Group on Rare Plasma Related Disorders that would meet regularly to ensure the unique challenges facing these patient groups are appropriately taken into account in relevant EU legislation and actions. Face-to-face consultation between EU decision makers and patients' groups facilitates a greater understanding of the challenges faced by patients and where the European Union can contribute and add value. This is reflected in the recently created liaison mechanisms between plasma related patient organisations and the European Commission.

5. In future communications, legislation and discussions in the European Union, the intrinsic differences between the collection of whole blood and the collection of plasma and the medicinal products derived from it should be considered carefully. The logical separation of whole blood and plasma will lead to a better understanding of the unique nature of the therapies for rare plasma related disorders, and ultimately better care and treatment for patients.

At the time of print, this Call for Action has been signed by the following 13 MEPs.

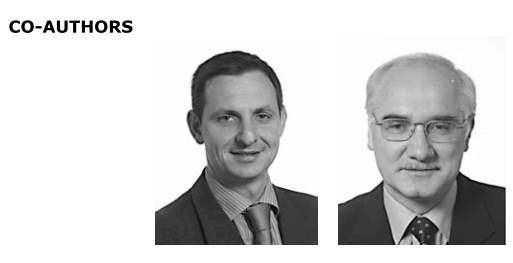

Jorgo Chatzimarkakis (ALDE, GERMANY)

SUPPORTING MEPS

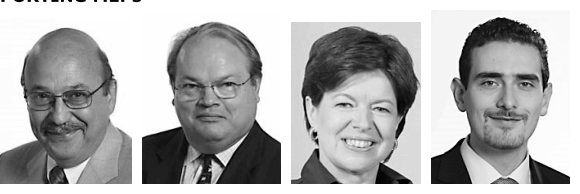

Adamos Adamou (GUE/NGL, CYPRUS), John Bowis (EPP-ED, UK) Frieda Brepoels (EPP-ED, BELGIUM), Magor Imre Csibi (ALDE, ROMANIA)

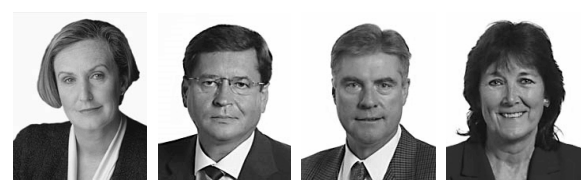

Avril Doyle (EPP-ED, IRELAND), Milan Gala (EPP-ED, SLOVAKIA) Stephen Hughes (PES, UK), Elizabeth Lynne (ALDE, UK)

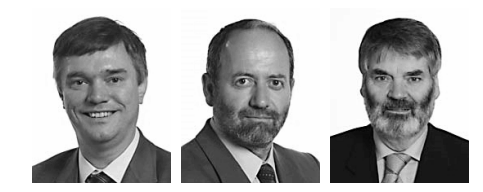

Marios Matsakis (ALDE, CYPRUS), Jules Maaten (ALDE, NETHERLANDS) proinsias DeRossa (PES, IRELAND) 